\title{
Hemoglobin and mortality in patients with COPD: a nationwide population-based cohort study
}

This article was published in the following Dove Press journal:

International Journal of COPD

\begin{abstract}
Seon Cheol Park, ${ }^{1,2}$ Young Sam Kim, ${ }^{3}$ Young Ae Kang, ${ }^{3}$ Eun Cheol Park, ${ }^{4}$ Cheung Soo Shin, ${ }^{5}$ Dong Wook Kim, ${ }^{6}$ Chin Kook Rhee ${ }^{7}$

'Division of Pulmonology, Department of Internal Medicine, National Health Insurance Service Ilsan Hospital, Goyang-si, Korea; ${ }^{2}$ Department of Medicine, Yonsei University College of Medicine, Seoul, Korea; ${ }^{3}$ Division of Pulmonology, Department of Internal Medicine, Yonsei University College of Medicine, Seoul, Korea; ${ }^{4}$ Department of Preventive Medicine, Yonsei University College of Medicine, Seoul, Korea; ${ }^{5}$ Department of Anesthesiology and Pain Medicine, Yonsei University College of Medicine, Seoul, Korea; ${ }^{6}$ Department of Policy Research Affairs, National Health Insurance Service Ilsan Hospital, Goyang-si, Korea; ${ }^{7}$ Division of Pulmonary, Allergy and Critical Care Medicine, Department of Internal Medicine, Seoul St Mary's Hospital, College of Medicine, The Catholic University of Korea, Seoul, Korea
\end{abstract}

Correspondence: Dong Wook Kim Department of Policy Research Affairs, National Health Insurance Service Ilsan Hospital, 100 Ilsan-ro, Ilsandong-gu,

Goyang-si, Gyeonggi-do I0444, Korea

Tel +82 3I 9006985

Fax +82319000343

Email kimdw2269@gmail.com

Chin Kook Rhee

Division of Pulmonary, Allergy and Critical Care Medicine, Department of Internal Medicine, Seoul St Mary's Hospital, College of Medicine, The Catholic University of Korea, 222 Banpo-daero, Seocho-gu, Seoul 0659l, Korea

Tel +82 222586067

Fax +82 25993589

Email chinkook77@gmail.com
Purpose: Previous studies have reported that anemia increased mortality in patients with COPD. However, it is unclear whether anemia is associated with increased COPD mortality in the general population. The purpose of our study is to identify whether anemia is related to long-term mortality in COPD using a large population-based database.

Patients and methods: Using the National Health Insurance Service-Health Screening Cohort, we identified COPD patients with available hemoglobin level. We analyzed mortality among patients with COPD from 2003 to 2013 according to hemoglobin level.

Results: A total of 7,114 patients with COPD were identified. Mean age was $65.0 \pm 9.3$ years, and $62.9 \%$ were male. Anemia was present in 469 patients $(6.6 \%)$. The overall mortality rate was $46.5 \%$ in anemia and $32.1 \%$ in non-anemia groups $(p<0.001)$. The hazard ratio of anemia for mortality was 1.31 (95\% CI, 1.11-1.54). Among patients with anemia, the hemoglobin level correlated well with mortality.

Conclusion: Anemia was associated with increased long-term mortality of COPD, and even mild anemia was related to a significantly increased risk.

Keywords: COPD, mortality, anemia, hemoglobin

\section{Introduction}

COPD was the third leading cause of death worldwide in $2010 .{ }^{1}$ Mortality in patients with COPD is related to various measures, including forced expiratory volume in 1 second, ratio of inspiratory to total lung capacities, exercise capacity, dyspnea scores, body mass index (BMI), and exacerbation frequency. ${ }^{2}$

Anemia is a well-known comorbidity of COPD. The prevalence of anemia in COPD ranges from $7.5 \%$ to $32.7 \% .^{3}$ Anemia reflects chronic illness and burden of disease, and COPD patients with anemia have an increased risk for poor outcomes. Previous studies have reported that anemia increased mortality in COPD; ${ }^{4-9}$ however, these studies only included patients who were receiving long-term oxygen therapy or required hospitalization or analyzed a small number of patients or short-term survival. To the best of our knowledge, no large-scale and population-based studies have evaluated the effect of anemia on the long-term survival of COPD.

The purpose of our study was to identify whether anemia is related to long-term mortality in COPD using a large population-based database. We also aimed to evaluate whether the degree of anemia affects the survival of patients with COPD.

\section{Materials and methods}

\section{Source of data}

Since 2000, the National Health Insurance Service (NHIS) in Korea has provided a health insurance service to nearly all people living in Korea. Consequently, a large 
amount of health-related data has accumulated in the NHIS system. Using this database, the Korean NHIS has established a research database. Because all Koreans have been recommended to undergo a national health screening every 2 years, the NHIS was able to generate a health screening cohort that was the NHIS-Health Screening (NHIS-Heals) database. From 2002 to 2003, a total of 5,150,000 people between the ages of 40 and 79 years received national health screening. Among them, 514,866 people were sampled and followed up from 2002 to 2013 for a research database, which was used for our study (Figure 1). NHIS-Heals database comprised a random selection of $10 \%(n=514,866)$ of all health screening participants $(n=5,150,000)$ in 2002 and 2003. This research database included data on socioeconomic status (household income), medical treatments, medical care institutions, and general health examinations. NHIS data is de-identified by government. This study was approved by the Institutional Review Board of NHIS Ilsan Hospital.

\section{Study population}

Because the NHIS database did not include spirometry data essential for the diagnosis of COPD and did not also include an individual's medical history or symptoms, we identified COPD patients using the International Classification of Disease-Tenth Revision (ICD-10) and prescription details in the health screening cohort. We used the diagnostic criteria that an individual should visit the medical facility at least twice per year with both a COPD diagnostic code and a prescription for 1 or more COPD medications. Similar to previous studies, ${ }^{10-13}$ COPD patients were identified by the presence of all of the following criteria: $>40$ years of age; ICD-10 codes for COPD (J43-J44, except J430); and COPD medication use at least twice per year. COPD medications include long-acting muscarinic antagonist, long-acting beta- 2 agonist (LABA), inhaled corticosteroid (ICS), ICS plus LABA, short-active muscarinic antagonist (SAMA), short-acting beta-2 agonist (SABA), SAMA plus SABA, methylxanthines, systemic corticosteroids, and systemic beta agonists. The national health screening cohort included laboratory data, from which we obtained the hemoglobin levels. Hemoglobin status was categorized as anemia or non-anemia according to the World Health Organization guidelines (anemia defined as hemoglobin $<12 \mathrm{~g} / \mathrm{dL}$ in females, $<13 \mathrm{~g} / \mathrm{dL}$ in males $).{ }^{14}$ The population with COPD or anemia in 2002 was excluded, and only patients with newly diagnosed COPD from 2003 to 2005 were enrolled. We followed these COPD patients from 2003 to 2013 to analyze the effect of anemia on COPD survival (Figure 1). All Koreans have been recommended to undergo a national health screening every 2 years; therefore, all individuals had 1 or 2 hemoglobin

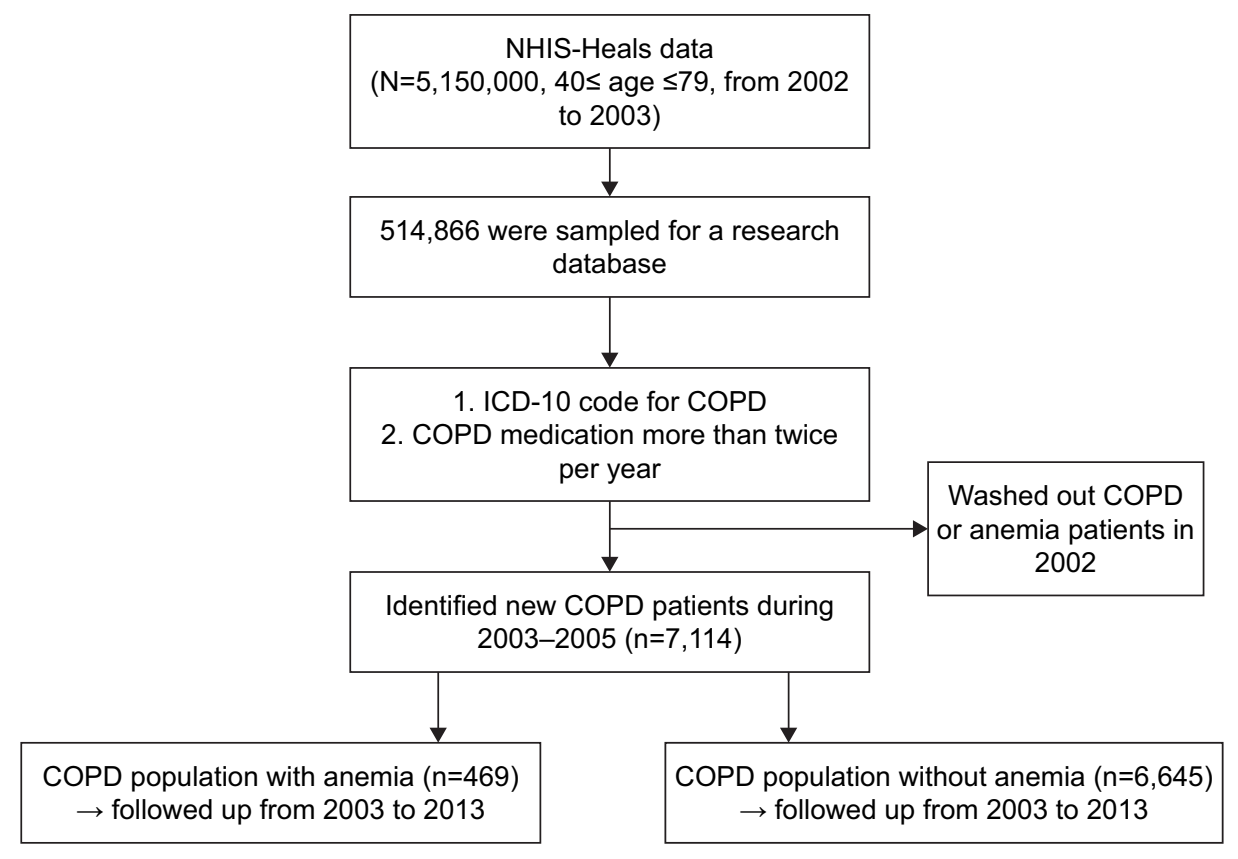

Figure I Flow chart of the study population.

Abbreviations: ICD-10, International Classification of Disease-Tenth Revision; NHIS-Heals, National Health Insurance Service-Health Screening. 
measurements from 2003 to 2005. If an individual had 2 measurements, we used the first hemoglobin result.

\section{Determinants of disease and demographic factors}

The demographic factors of COPD patients were analyzed at the time of COPD diagnosis and first health screening visits. Socioeconomic status was divided into 5 categories according to household income. Charlson comorbidity index (CCI) was calculated according to a previous study. ${ }^{15} \mathrm{BMI}$ was calculated based on height and body weight. The patients were categorized as underweight $(\mathrm{BMI}<18.5)$, normal (18.5-22.9), overweight (23-24.9), obese I (25.0-29.9), or obese II $(\geq 30) .{ }^{16}$ Smoking status was divided into 3 groups according to a health questionnaire completed at the first health screening visit. Never-smokers were defined as those who answered that they had never smoked. Ex-smokers were defined as those who answered that they had smoked before, but did not smoke at the time of the health screening visit. Current smokers were defined as those who answered that they smoked at the time of the health screening visit.

\section{Study outcomes}

Patients were enrolled at the time of COPD diagnosis and followed up until the end of the study period or death. The monthly mortality was compared between anemic and nonanemic groups from 2003 to 2013. We also analyzed the effect of different hemoglobin levels on mortality.

\section{Statistical analysis}

Differences between groups were assessed using the Chi-square test for categorical variables and Student's $t$-test for continuous variables. A Cox proportional hazards model was used to identify independent variables for mortality of COPD. Results were presented as hazard ratio (HR) and $95 \%$ CI. Violation of proportional hazards assumption was tested by exploring $\log (-\log$ [survival]) curves. A $p$-value $<0.05$ was considered statistically significant. All statistical analyses were performed with the SAS program, version 9.4 (SAS Institute, Cary, NC, USA).

\section{Results}

\section{Study population}

A total of 7,114 patients with COPD were included during

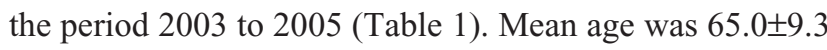
years, and $62.9 \%$ were male. Anemia was present in 469 $(6.6 \%)$ patients. Gender distribution was similar between
Table I Demographic and clinical characteristics of COPD patients with or without anemia

\begin{tabular}{|c|c|c|c|}
\hline Variable & $\begin{array}{l}\text { Anemia } \\
(n=469)\end{array}$ & $\begin{array}{l}\text { Non-anemia } \\
(n=6,645)\end{array}$ & $p$-value \\
\hline$\overline{\text { Male }}$ & $291(62.1)$ & $4,185(63.0)$ & 0.686 \\
\hline Age (years) & $67.8 \pm 8.6$ & $64.8 \pm 9.3$ & $<0.001$ \\
\hline $40-49$ & $21(4.5)$ & $552(8.3)$ & \\
\hline $50-59$ & $51(10.9)$ & I,I54 (I7.4) & \\
\hline $60-69$ & $172(36.7)$ & $2,666(40.1)$ & \\
\hline$\geq 70$ & $225(48.0)$ & $2,273(34.2)$ & \\
\hline Hemoglobin (mg/dL) & $\mid 1.5 \pm 1.1$ & $14.2 \pm 1.2$ & $<0.001$ \\
\hline Household income & & & 0.064 \\
\hline$<20 \%$ & $120(25.6)$ & I,328 (20.0) & \\
\hline $20 \%-39 \%$ & $78(16.6)$ & I,I33 (17.1) & \\
\hline $40 \%-59 \%$ & $69(14.7)$ & 1,040 & \\
\hline $60 \%-79 \%$ & $90(19.2)$ & I,35I (20.3) & \\
\hline$\geq 80 \%$ & $112(23.9)$ & I,793 (27.0) & \\
\hline $\mathrm{CCl}$ & & & $<0.001$ \\
\hline I & $112(23.9)$ & $2,437(36.7)$ & \\
\hline 2 & $171(36.5)$ & $2,50 I(37.6)$ & \\
\hline 3 & $128(27.3)$ & I, $192(17.9)$ & \\
\hline$\geq 4$ & $58(12.4)$ & $515(7.8)$ & \\
\hline BMI $\left(\mathrm{kg} / \mathrm{m}^{2}\right)$ & & & $<0.001$ \\
\hline$<18.5$ & $88(18.9)$ & $182(6.9)$ & \\
\hline $18.5-22.9$ & $203(43.5)$ & 994 (37.7) & \\
\hline $23.0-24.9$ & $80(17.1)$ & $648(24.6)$ & \\
\hline $25.0-29.9$ & $87(18.6)$ & $734(27.8)$ & \\
\hline$\geq 30.0$ & $9(1.9)$ & $81(3.1)$ & \\
\hline Smoking & & & 0.109 \\
\hline Never & $303(67.5)$ & I,584 (62.9) & \\
\hline Ex & $45(10.0)$ & $328(13.0)$ & \\
\hline Current & $101(22.5)$ & $608(24.1)$ & \\
\hline Deaths & $218(46.5)$ & $2,132(32.1)$ & $<0.001$ \\
\hline
\end{tabular}

Note: Data are shown as the mean \pm SD or number (\%).

Abbreviations: $\mathrm{BMI}$, body mass index; $\mathrm{CCl}$, Charlson comorbidity index.

anemia and non-anemia groups, but elderly patients were more frequent in the anemic group. Mean hemoglobin level was $11.5 \pm 1.1 \mathrm{~g} / \mathrm{dL}$ in the anemia group and $14.2 \pm 1.2 \mathrm{~g} / \mathrm{dL}$ in the non-anemia group. Anemic patients had higher CCI and lower BMI. Overall, patients in the anemia group were older and more likely to have chronic illness than those in the non-anemia group.

\section{Mortality}

The overall mortality rate during the study period was $46.5 \%$ in the anemia group and $32.1 \%$ in the non-anemia group. The mean follow-up duration was $100.0 \pm 36.5$ months $(87.7 \pm 39.9$ in anemia vs $100.8 \pm 36.1$ in non-anemia). Table 2 showed a Cox proportional hazards model for factors associated with mortality in COPD patients. In multivariate analysis, overall mortality was associated with old age, low socioeconomic status, high CCI, low BMI, and anemia. The HR of anemia for mortality was 1.31 (95\% CI, 1.11-1.54). Lower hemoglobin 
Table 2 Cox proportional hazards model for factors associated with mortality in COPD patients

\begin{tabular}{|c|c|c|c|c|c|c|}
\hline \multirow[t]{2}{*}{ Variable } & \multicolumn{2}{|l|}{ Univariate } & \multicolumn{2}{|c|}{ Multivariate (anemia) } & \multicolumn{2}{|c|}{ Multivariate (hemoglobin) } \\
\hline & HR (95\% Cl) & $p$-value & HR (95\% Cl) & $p$-value & HR (95\% Cl) & $p$-value \\
\hline Anemia & $1.69(1.47-1.95)$ & $<0.001$ & $1.31(1.11-1.54)$ & 0.002 & - & - \\
\hline \multicolumn{7}{|c|}{ Hemoglobin (mg/dL) } \\
\hline$\geq 13.0$ & I & & - & - & 1 & \\
\hline $11.0-12.9$ & $1.17(1.02-1.36)$ & 0.031 & - & - & $1.23(1.04-1.45)$ & 0.017 \\
\hline $9.0-10.9$ & $1.57(1.10-2.25)$ & 0.014 & - & - & $1.62(1.10-2.39)$ & 0.014 \\
\hline 7.0-8.9 & $3.48(1.97-6.16)$ & $<0.001$ & - & - & $2.74(1.53-4.88)$ & 0.001 \\
\hline$<7.0$ & $5.09(1.27-20.35)$ & 0.022 & - & - & $5.12(1.25-20.97)$ & 0.023 \\
\hline Female & $0.44(0.40-0.48)$ & $<0.001$ & $0.48(0.4 \mathrm{I}-0.57)$ & $<0.001$ & $0.44(0.36-0.53)$ & $<0.001$ \\
\hline \multicolumn{7}{|l|}{ Age (years) } \\
\hline $40-49$ & 1 & & I & & I & \\
\hline $50-59$ & $2.74(1.77-4.23)$ & $<0.001$ & $3.18(1.57-6.42)$ & 0.001 & $3.19(1.58-6.45)$ & 0.001 \\
\hline $60-69$ & 7.97 (5.3I-II.95) & $<0.001$ & 7.89 (4.07-15.32) & $<0.001$ & $7.88(4.05-15.30)$ & $<0.001$ \\
\hline$\geq 70$ & $19.25(\mid 2.87-28.8 I)$ & $<0.001$ & I 8.77 (9.70-36.33) & $<0.00$ I & 18.86 (9.77-36.52) & $<0.001$ \\
\hline \multicolumn{7}{|c|}{ Household income } \\
\hline$<20 \%$ & I & & I & & I & \\
\hline $20 \%-39 \%$ & $0.90(0.79-1.02)$ & 0.115 & $0.90(0.74-1.10)$ & 0.322 & $0.90(0.74-1.10)$ & 0.310 \\
\hline $40 \%-59 \%$ & $0.79(0.69-0.91)$ & 0.001 & $0.77(0.62-0.96)$ & 0.019 & $0.76(0.6 \mathrm{I}-0.95)$ & 0.016 \\
\hline $60 \%-79 \%$ & $0.80(0.7|-0.9|)$ & 0.001 & $0.79(0.65-0.96)$ & 0.020 & $0.79(0.65-0.97)$ & 0.022 \\
\hline$\geq 80 \%$ & $0.84(0.75-0.94)$ & 0.003 & $0.82(0.68-0.99)$ & 0.035 & $0.82(0.68-0.98)$ & 0.032 \\
\hline \multicolumn{7}{|l|}{$\mathrm{CCl}$} \\
\hline 1 & 1 & & 1 & & I & \\
\hline 2 & $1.07(0.97-1.18)$ & 0.181 & $1.09(0.97-1.28)$ & 0.261 & $1.09(0.93-1.27)$ & 0.274 \\
\hline 3 & $1.37(1.22-1.53)$ & $<0.001$ & $1.22(1.01-1.47)$ & 0.042 & $1.20(1.00-1.45)$ & 0.057 \\
\hline$\geq 4$ & $2.04(1.78-2.35)$ & $<0.001$ & $1.33(1.03-1.71)$ & 0.027 & $1.34(1.04-1.72)$ & 0.023 \\
\hline \multicolumn{7}{|l|}{ BMI $\left(\mathrm{kg} / \mathrm{m}^{2}\right)$} \\
\hline$<18.5$ & I & & I & & 1 & \\
\hline $18.5-22.9$ & $0.45(0.38-0.53)$ & $<0.001$ & $0.54(0.45-0.57)$ & $<0.00$ I & $0.54(0.45-0.65)$ & $<0.001$ \\
\hline $23.0-24.9$ & $0.28(0.23-0.34)$ & $<0.001$ & $0.42(0.34-0.53)$ & $<0.001$ & $0.43(0.34-0.53)$ & $<0.001$ \\
\hline $25.0-29.9$ & $0.21(0.17-0.26)$ & $<0.001$ & $0.34(0.27-0.43)$ & $<0.001$ & $0.35(0.28-0.44)$ & $<0.001$ \\
\hline$\geq 30.0$ & $0.12(0.07-0.23)$ & $<0.001$ & $0.27(0 . \mid 5-0.5 \mathrm{I})$ & $<0.001$ & $0.27(0.15-0.50)$ & $<0.001$ \\
\hline \multicolumn{7}{|l|}{ Smoking } \\
\hline Never & I & & I & & I & \\
\hline Ex & $1.47(1.22-1.78)$ & $<0.001$ & $1.07(0.88-1.30)$ & 0.500 & I.08 (0.89-|.3|) & 0.466 \\
\hline Current & $1.40(1.20-1.62)$ & $<0.001$ & $1.03(0.88-1.21)$ & 0.676 & $1.03(0.88-|.2|)$ & 0.684 \\
\hline
\end{tabular}

Abbreviations: BMI, body mass index; $\mathrm{CCl}$, Charlson comorbidity index; $\mathrm{HR}$, hazard ratio.

levels were also associated with increased mortality regardless of anemia severity. The HR for death in patients with a hemoglobin value between 11.0 and $13.0 \mathrm{~g} / \mathrm{dL}$ compared with a hemoglobin value over $13.0 \mathrm{~g} / \mathrm{dL}$ was $1.23(95 \%$ CI, 1.04-1.45). Patients with hemoglobin $<7 \mathrm{~g} / \mathrm{dL}$ had an approximately 5 -fold higher risk of death than non-anemic patients. Figure 2 shows the Kaplan-Meier survival curves for anemia and non-anemia. The survival rate of anemia group was lower than that of the non-anemia group. The 5-year survival rate was 0.72 in the anemia group and 0.84 in the non-anemia group. Figure 3 shows the data for different hemoglobin levels. These show a clear difference in survival rate according to hemoglobin. Even in anemia patients, the decrease in hemoglobin level was closely related to the decrease in survival rate. When we analyzed the HR for mortality using continuous hemoglobin values $(\mathrm{g} / \mathrm{dL})$, the HR of hemoglobin for mortality was $0.92(95 \%$ CI, 0.86-0.96).

\section{Discussion}

To the best of our knowledge, this is the first study that evaluated the long-term effect of anemia on COPD survival in the general population. Our data showed that the prevalence of anemia in COPD was $6.6 \%$ and that anemia was associated with increased long-term mortality. Hemoglobin level was well correlated with mortality. Even a mild decrease in hemoglobin increased the risk of death, and the risk of mortality increased in proportion to the decrease in hemoglobin.

Although anemia is a well-known comorbidity of COPD, studies on the impact of hemoglobin on COPD mortality are 


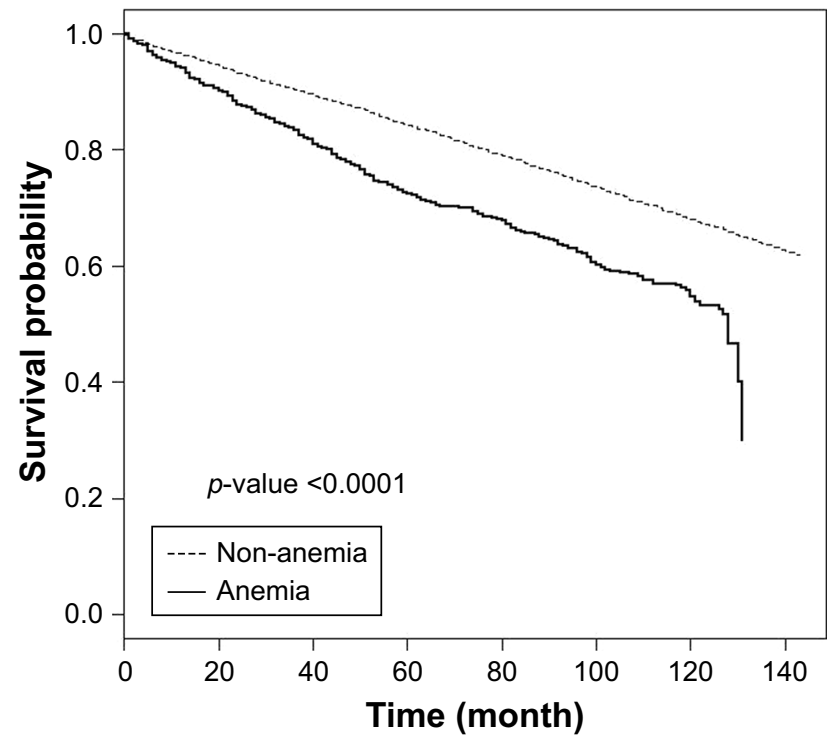

Figure 2 Kaplan-Meier survival curves for anemia and non-anemia.

lacking, and the characteristics of populations in previous studies were highly variable. Overall, studies have shown a trend for increased mortality in COPD patients with anemia. However, most studies had retrospective designs, included patients who were receiving long-term oxygen therapy or required hospitalization, or analyzed a small number of patients or short-term survival. Overall, previous studies might be categorized into 3 broad groups: COPD patients with long-term oxygen therapy or non-invasive ventilation; stable COPD outpatients; and hospitalized COPD patients with acute exacerbation.

The pivotal study analyzing the long-term effect of anemia on COPD mortality was conducted by Chambellan et al. ${ }^{4}$ They

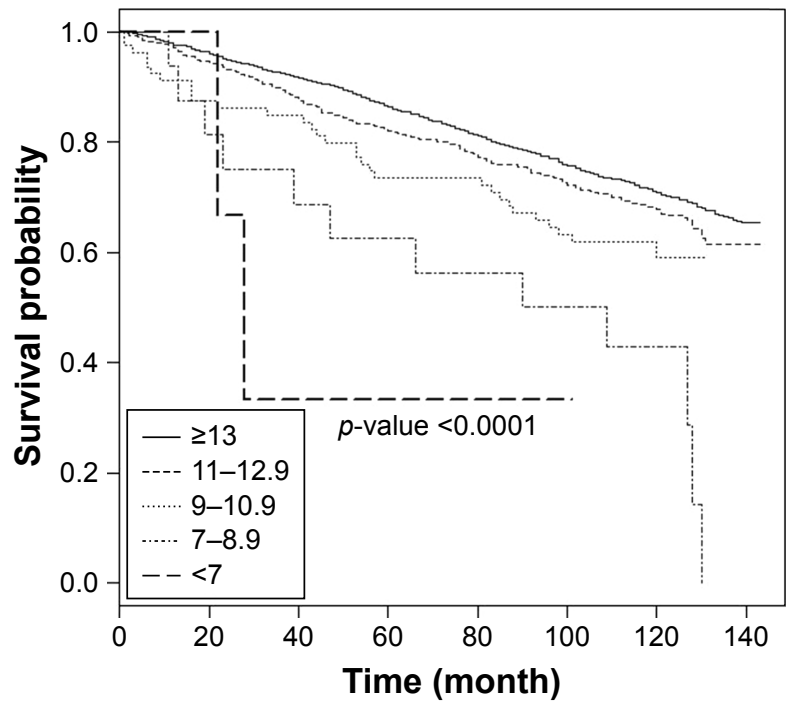

Figure 3 Kaplan-Meier survival curves by different hemoglobin levels. used the ANTADIR (Association Nationale pour le Traitement a Domicile de l'Insuffisance Respiratoire) database, which was generated from the French national home-care system for patients requiring oxygen support or mechanical ventilation. Among COPD patients receiving long-term oxygen therapy, the prevalence of anemia was $12.6 \%$ in men and $8.2 \%$ in women. The hematocrit was an independent predictor of survival, hospital admission rate, and cumulative duration of hospitalization in this population. The long-term survival rate decreased with lower hematocrit levels. Kollert et al analyzed similar patients who had severe COPD and chronic respiratory failure with non-invasive ventilation. ${ }^{17}$ They reported that high hemoglobin level prior to the initiation of non-invasive ventilation was associated with better long-term survival. The optimal cutoff value for prediction of death was $14.3 \mathrm{~g} / \mathrm{dL}$ for females and $15.1 \mathrm{~g} / \mathrm{dL}$ for males.

The effect of anemia on mortality for stable COPD outpatients has also been reported. Cote et al reported hemoglobin level and its clinical impact for stable COPD outpatients in a USA Veterans Administration pulmonary clinic. ${ }^{18}$ The number of total COPD patients was 683 , and anemia was present in $116(17 \%)$. Anemia was independently associated with increased dyspnea and reduced the 6-minute walking distance; however, it was not a significant independent predictor of mortality. Boutou et al also conducted a retrospective study to evaluate the association between anemia and survival in stable COPD outpatients. ${ }^{7}$ Of a total 294 COPD patients, $46(15.6 \%)$ had anemia. Anemia was an independent predictor of mortality (HR 1.87, 95\% CI, 1.06-3.29) and was associated with shorter median survival.

The association between anemia and mortality in hospitalized COPD patients has been recently evaluated. MartinezRivera et al reported that anemia and previous exacerbations were independent predictors of 1-year mortality in hospitalized COPD patients. ${ }^{6}$ Patients with anemia had a relative risk of death of 5.9 (95\% CI, 1.9-18.9). Toft-Petersen et al similarly reported that a lower hemoglobin level at admission was related to higher risk of long-term mortality after discharge. ${ }^{9}$ Some studies have evaluated short-term mortality in anemic COPD patients with hospitalization. Rasmussen et al evaluated the 90-day mortality among COPD patients who needed invasive mechanical ventilation..$^{5}$ In these patients, anemia was associated with increased mortality, and the adjusted 90-day mortality risk ratio was 2.6 (95\% CI, 1.5-4.5). Ergan and Ergün also reported that anemia was a risk factor of in-hospital death in COPD patients requiring mechanical ventilation. ${ }^{8}$ In multivariate analysis, the odds ratio of anemia for hospital mortality was 3.99 (95\% CI, 1.4-11.4). 
Previous studies have reported the prevalence of anemia in COPD ranging from $7.5 \%$ to $32.7 \% .^{3}$ The prevalence in our study was $6.6 \%$. Anemia reflects chronic illness and burden of disease, and our cohort included a relatively healthy population who regularly underwent the national health screening examination. The patients included in this study were newly diagnosed patients with COPD and probably milder than other cohorts previously reported. Therefore, the prevalence in our study might be lower than in other studies. Interestingly, other studies on stable outpatients with COPD have reported a prevalence of anemia ranging from $15.6 \%$ to $17.1 \%$. $^{7,18}$

Although several studies have shown that anemia in COPD is related to increased mortality, to our knowledge, there are no studies that evaluated the association between anemia and long-term mortality of COPD in the general population. Our study also included a larger number of COPD patients with long-term follow-up compared with previous studies. Our results are significant in that anemia increases mortality even in the general COPD population who do not require oxygen therapy, hospitalization, or frequent healthcare use. We also showed that even a mild decrease in hemoglobin increased the risk of death. Toft-Petersen et al reported similar results. ${ }^{9}$ They showed that a decrease in hemoglobin by only $1 \mathrm{~g} / \mathrm{dL}$ compared with the normal value had an HR for death of 1.37 (95\% CI, 1.15-1.64) in males and 1.28 (95\% CI, 1.06-1.53) in females.

Our study has some limitations. First, we could not use spirometry data, but used only ICD-10 codes and medications for COPD diagnosis. However, this working definition has been utilized and validated in many previous studies. ${ }^{10-13} \mathrm{We}$ could not also use an individual's medical history or symptoms that might be helpful for COPD diagnosis. Second, confounding factors could have affected the mortality. COPD mortality is associated with various factors. We attempted to control for possible confounders, such as socioeconomic status, CCI, BMI, and smoking; however, other factors were not examined. Especially, we did not include the important comorbidities of COPD that may have influenced mortality. Moreover, anemia has numerous causes that may be confounders, and we could not exclude patients with comorbidity associated with anemia. Third, this is a retrospective observational study and so could involve missing data or follow-up loss. However, in the NHIS database, every detail of healthcare utilization was recorded without any missing data. Moreover, since national insurance is mandatory by law, almost the entire population in Korea can be followed in the NHIS database without loss. This advantage of the NHIS database can increase the value of the results obtained in this study.

\section{Conclusion}

Our large population-based study showed that anemia was associated with increased long-term mortality of COPD. Even mild anemia was related to a significantly increased risk of death. Hemoglobin level was well correlated with risk of death. More studies are needed to prospectively evaluate the effects of anemia on COPD mortality.

\section{Acknowledgment}

This study used NHIS-HealS data (NHIS-2017-2-406) made by NHIS.

\section{Disclosure}

The authors report no conflicts of interest with NIHS and with this work.

\section{References}

1. Lozano R, Naghavi M, Foreman K, et al. Global and regional mortality from 235 causes of death for 20 age groups in 1990 and 2010: a systematic analysis for the Global Burden of Disease Study 2010. Lancet. 2012;380:2095-2128.

2. Berry CE, Wise RA. Mortality in COPD: causes, risk factors, and prevention. COPD. 2010;7:375-382.

3. Yohannes AM, Ershler WB. Anemia in COPD: a systematic review of the prevalence, quality of life, and mortality. Respir Care. 2011;56: 644-652.

4. Chambellan A, Chailleux E, Similowski T. Prognostic value of the hematocrit in patients with severe COPD receiving long-term oxygen therapy. Chest. 2005;128:1201-1208.

5. Rasmussen L, Christensen S, Lenler-Petersen P, Johnsen SP. Anemia and 90-day mortality in COPD patients requiring invasive mechanical ventilation. Clin Epidemiol. 2010;3:1-5.

6. Martinez-Rivera C, Portillo K, Muñoz-Ferrer A, et al. Anemia is a mortality predictor in hospitalized patients for COPD exacerbation. COPD. 2012;9:243-250.

7. Boutou AK, Karrar S, Hopkinson NS, Polkey MI. Anemia and survival in chronic obstructive pulmonary disease: a dichotomous rather than a continuous predictor. Respiration. 2013;85:126-131.

8. Ergan B, Ergün R. Impact of anemia on short-term survival in severe COPD exacerbations: a cohort study. Int JChron Obstruct Pulmon Dis. 2016;11:1775-1783.

9. Toft-Petersen AP, Torp-Pedersen C, Weinreich UM, Rasmussen BS. Association between hemoglobin and prognosis in patients admitted to hospital for COPD. Int J Chron Obstruct Pulmon Dis. 2016;11: 2813-2820.

10. Kim J, Lee JH, Kim Y, et al. Association between chronic obstructive pulmonary disease and gastroesophageal reflux disease: a national cross-sectional cohort study. BMC Pulm Med. 2013;13:51.

11. Kim J, Rhee CK, Yoo KH, et al. The health care burden of high grade chronic obstructive pulmonary disease in Korea: analysis of the Korean Health Insurance Review and Assessment Service data. Int J Chron Obstruct Pulmon Dis. 2013;8:561-568.

12. Kim J, Kim K, Kim Y, et al. The association between inhaled longacting bronchodilators and less in-hospital care in newly-diagnosed COPD patients. Respir Med. 2014;108:153-161.

13. Rhee CK, Yoon HK, Yoo KH, et al. Medical utilization and cost in patients with overlap syndrome of chronic obstructive pulmonary disease and asthma. COPD. 2014;11:163-170. 
14. World Health Organization. Haemoglobin Concentrations for the Diagnosis of Anaemia and Assessment of Severity. Vitamin and Mineral Nutrition Information System. Geneva: World Health Organization; 2011. Available from: http://www.who.int/vmnis/indicators/haemoglobin.pdf. Accessed August 17, 2017.

15. Charlson ME, Pompei P, Ales KL, MacKenzie CR. A new method of classifying prognostic comorbidity in longitudinal studies: development and validation. J Chronic Dis. 1987;40:373-383.

16. Anuurad E, Shiwaku K, Nogi A, et al. The new BMI criteria for Asians by the regional office for the western pacific region of WHO are suitable for screening of overweight to prevent metabolic syndrome in elder Japanese workers. J Occup Health. 2003;45:335-343.
17. Kollert F, Tippelt A, Müller C, et al. Hemoglobin levels above anemia thresholds are maximally predictive for long-term survival in COPD with chronic respiratory failure. Respir Care. 2013;58:1204-1212.

18. Cote C, Zilberberg MD, Mody SH, Dordelly LJ, Celli B. Haemoglobin level and its clinical impact in a cohort of patients with COPD. Eur Respir J. 2007;29:923-929.

International Journal of COPD

\section{Publish your work in this journal}

The International Journal of COPD is an international, peer-reviewed journal of therapeutics and pharmacology focusing on concise rapid reporting of clinical studies and reviews in COPD. Special focus is given to the pathophysiological processes underlying the disease, intervention programs, patient focused education, and self management protocols.

\section{Dovepress}

This journal is indexed on PubMed Central, MedLine and CAS. The manuscript management system is completely online and includes a very quick and fair peer-review system, which is all easy to use. Visit http://www.dovepress.com/testimonials.php to read real quotes from published authors.

Submit your manuscript here: http://www.dovepress.com/international-journal-of-chronic-obstructive-pulmonary-disease-journal 